\title{
Eating habits and nutrition structure of high school and college students living in the Arctic zone of Russia
}

\author{
Olga B. Khoreva ${ }^{1}$, Tamara G. Nezhina ${ }^{1}$, Elena A. Tarasenko ${ }^{1}$, \\ Ekaterina N. Tamitskaya ${ }^{2}$, Konstantin S. Zaykov², \\ 1 HSE, Moscow, 109028, Russia \\ 2 Northern (Arctic) Federal University named after M.V. Lomonosov, Arkhangelsk, 163002, Russia
}

Received 26 January 2021 • Accepted 14 March 2021 • Published 31 March 2021

Citation: Khoreva OB, Nezhina TG, Tarasenko EA, Tamitskaya EN, Zaykov KS (2021) Eating habits and nutrition structure of high school and college students living in the Arctic zone of Russia. Population and Economics 1(5): 40-48. https://doi.org/10.3897/popecon.5.e65922

\begin{abstract}
The research note focuses on the issues of eating behaviour of young people in Arkhangelsk. The authors analyze the dynamics of general indicators of morbidity and mortality from diseases of the digestive system in the regions of the Arctic zone and substantiate the relevance of nutrition studies in these regions. Based on the results of the survey conducted in 2018 at schools, colleges and universities in Arkhangelsk, the authors show that a significant part of the youth have irregular eating habits and characterise the structure of their own nutrition as unsatisfactory. University students show a greater commitment to balanced nutrition than college students, but it is college and university students that disregard frequency of nutrition, which can be a consequence of inadequate catering arrangement and its affordability at local schools.
\end{abstract}

\section{Keywords}

Arctic zone of Russia, regional policy, nutrition of students, nutrition structure, healthy eating, eating habits, youth health

JEL codes: I12; I14; I15

\section{Introduction}

Unhealthy, monotonous, energetically unbalanced nutrition with high trans fat, sugar, and salt content, predominance of processed foods, as well as low motor activity of the population are, according to the World Health Organization, the main causes of the growing pre- 
valence of non-communicable diseases and the decline in life expectancy of the population (WHO 2014).

In this regard, an early promotion of a healthy diet culture and the formation of proper food habits that contribute to the preservation of health, the prevention of non-communicable diseases, including diabetes, cardiovascular and oncological diseases, are one of the most important public health care challenges. This is reflected in international documents such as, for example, the World Health Organization's Global Strategy on Diet, Physical Activity and Health, adopted in 2004.

Formation of proper eating habits at a young age has an impact on human health throughout life, and therefore is the most effective in terms of preserving the health of the population. The bulk of foreign national campaigns promoting healthy eating among children and young people (e.g., 5 A Day campaign in the UK) are based on the theory of planned behaviour developed by Icek Ajzen in the late 1980s (Ajzen 1985, 1991), and its developments in the field of dietary patterns on its basis (McDermott et al. 2015).

The spread of healthy eating patterns among young people, according to Western researchers, is restrained by the scarcity of knowledge in the field of healthy eating (Abraham et al. 2018), propensity to reproduce unhealthy eating patterns adopted in their families (Barnes et al. 2012), as well as a wide selection of harmful, so-called "junk" food on store shelves (Das, Evans 2014) and its aggressive marketing by manufacturers.

In Russia, little research is devoted to eating behaviour of the youth. The majority of papers considering these issues to one degree or another are related to health literacy (Syrtsova et al. 2016), values of the youth (Shabunova, Korchagina 2012), dependence of the population health on the economic value of a person, self-preservation behaviour, and healthy lifestyle practices in general (Mironova 2016).

The authors of this paper focus on the study of the Arctic zone of Russia, which includes (entirely or partially) the municipalities of Arkhangelsk Oblast, the Nenets Autonomous Okrug, Murmansk Oblast, the Republics of Karelia and Komi, the Yamalo-Nenets Autonomous Okrug, Krasnoyarsk Krai, the Republic of Sakha (Yakutia), and the Chukotka Autonomous Okrug. It is known that living in the climatic conditions of the Arctic zone is a factor, which has a potentially adverse impact on health by itself. Thus, the following natural and climatic factors, the intensity of harmful effects of which can be reduced or compensated by preventive measures, are distinguished: deficiency of certain vitamins in traditional types of food products, low content of minerals in drinking water (almost distilled water), shortage of fresh vegetable products containing fiber in the structure of nutrition (Chashchin et al. 2014). Some studies confirm the relevance of the identified problems in this region: thus, Palmira Petrova, when conducting the daily monitoring of nutrition in the indigenous population of the Republic of Sakha (Yakutia), identified an imbalanced diet and insufficient supply of basic food products to a large proportion of the population (Petrova 2019). In this regard, the analysis of the situation in the Arctic zone is of particular interest.

The importance of promoting the culture of healthy eating among young people is due, inter alia, to the growing incidence of endocrine diseases, eating disorders and metabolism disorders, diseases of the digestive system in adolescents, as well as to high levels of mortality from diseases of the digestive system observed among population of working age.

In Russia, the incidences of endocrine diseases, eating disorders, and metabolic disorders among adolescents aged 15-17 years have been increasing since 2008. In the Arctic zone, the maximum values of morbidity for this group over the period under review were noted in 2012 in the Republic of Sakha (Yakutia), the Republic of Karelia, the Yamalo-Nenets Auton- 
omous Okrug and Arkhangelsk Oblast. In 2016, among all Arctic regions, only Arkhangelsk Oblast showed morbidity above average Russian level. At the same time, in most regions of the Arctic zone of the Russian Federation, with the exception of Arkhangelsk Oblast and the Chukotka Autonomous Okrug, the incidence of the considered diseases among adolescents decreased in 2008-2016 (Fig. 1).

The maximum incidence of diseases of the digestive system among adolescents aged 15-17 years in 2016 was also noted in Arkhangelsk Oblast, and the minimum in Murmansk Oblast (Fig. 2). At the same time, indicators above the national average for Russia in 2016

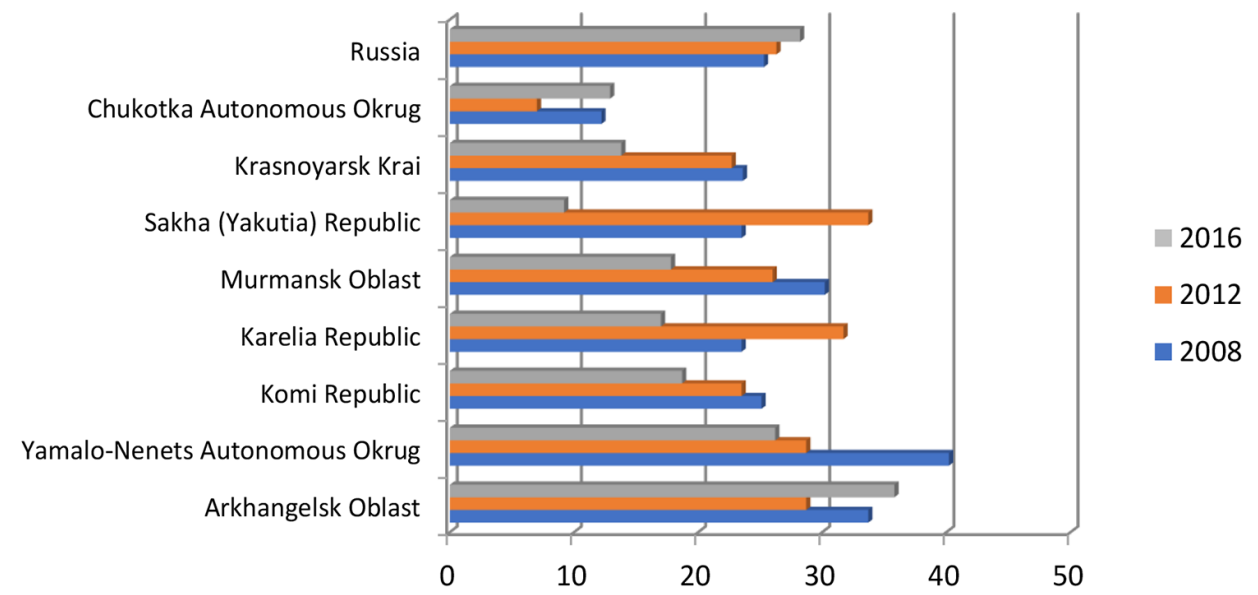

Figure 1. Incidence of endocrine system diseases, eating disorders, and metabolic disorders among adolescents aged 15-17 years in the regions of the Arctic zone of the Russian Federation, 2000-2016 (registered patients with first-time diagnosis per 1,000 adolescents). Source: Federal State Statistics Service. Healthcare in Russia (2017).

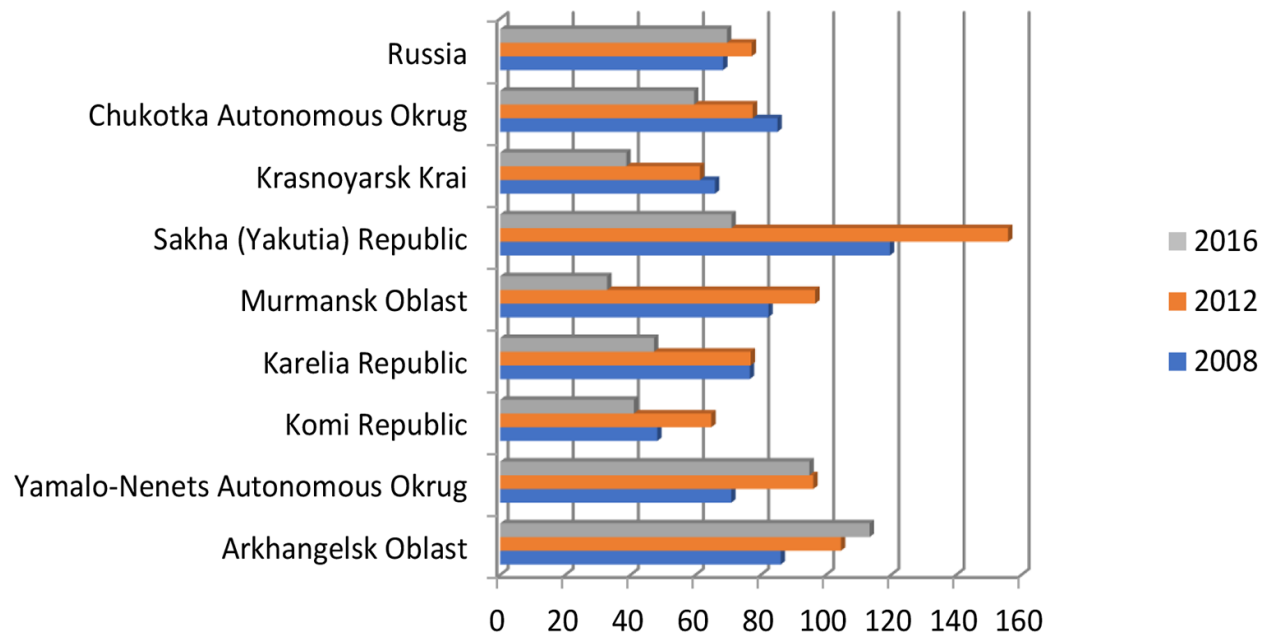

Figure 2. Incidence of digestive diseases among adolescents aged 15-17 years in the regions of the Arctic zone of the Russian Federation, 2000-2016 (registered patients with first-time diagnosis per 1,000 adolescents). Source: Federal State Statistics Service. Healthcare in Russia (2017). 
were noted in the Republic of Sakha (Yakutia), the Yamalo-Nenets Autonomous Okrug, and Arkhangelsk Oblast. However, only in Arkhangelsk Oblast indicator grew over the observed period.

Morbidity in the regions of northern Russia can be influenced by a number of factors. These include the provision of medical institutions with modern equipment, the presence of professional staff in medical institutions, and the prevalence of preventive medical examinations; all these factors affect the disease detection. Apart from that, the reported incidence rates are affected by the development of commercial medicine and paid medical services.

An additional source of information in this situation can be mortality statistics by cause. Figure 3 provides information on the dynamics of crude mortality rates from diseases of the digestive system (gastric ulcer, gastritis, fibrosis and liver cirrhosis, etc.) in the regions of the Arctic zone. In 2010, these rates were below the Russian average only in Yamalo-Nenets Autonomous Okrug, and the maximum values were noted in Chukotka Autonomous Okrug and the Republic of Komi. Over the observed period, a decrease in mortality from diseases of the digestive system was noted in Chukotka Autonomous Okrug, the Republic of Sakha (Yakutia), Murmansk oblast, and (a slight decrease) in Arkhangelsk oblast. Five of the eight regions under review showed an increase in 2016 compared to 2012 (Fig. 3). At the same time, in Yamalo-Nenets Autonomous Okrug, the Republic of Komi, and Krasnoyarsk Krai, the increase in mortality from diseases of the digestive system has been observed since 2012, and in Arkhangelsk Oblast and the Republic of Sakha (Yakutia) - since 2014.

The crude mortality rates depend significantly on the age structure of the population under review, and a more accurate picture requires a more detailed assessment based on standardized crude mortality rates or age-specific mortality rates. Given the specificity of the age and sex structure of the population in the northern regions, the transition to such indicators can significantly change the picture. Yet even these preliminary assessments, in our opinion, prove the relevance of studies of eating behaviour of the population - particularly of young people - in the Arctic zone.

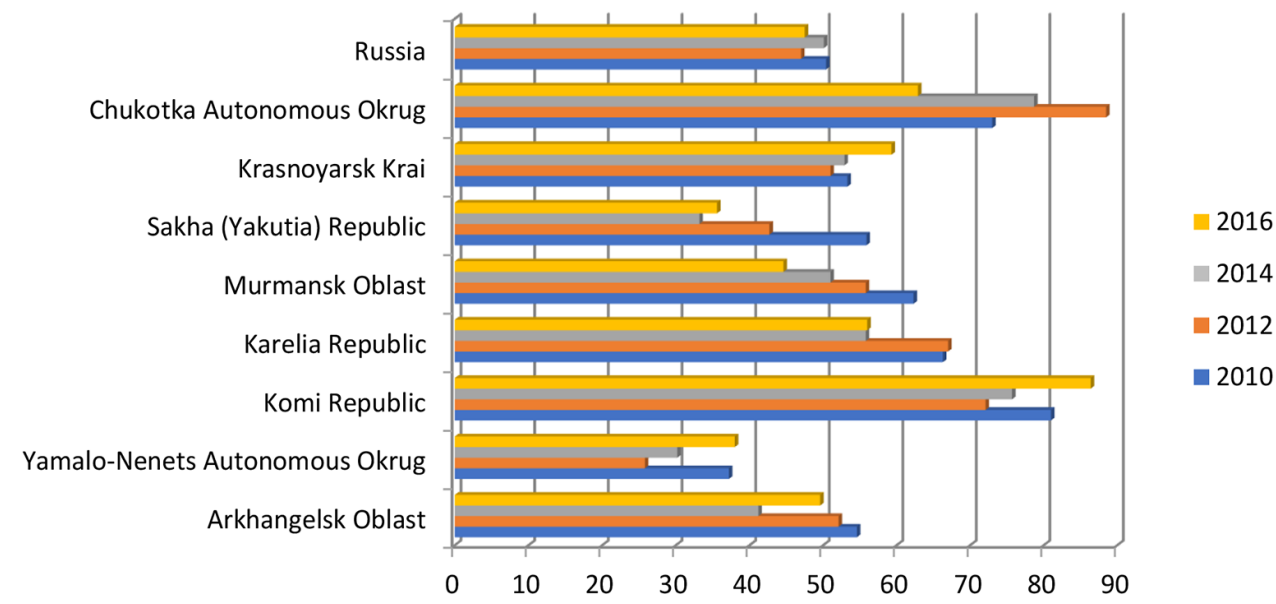

Figure 3. Crude mortality rates from diseases of the digestive system among the population of working age in the regions of the Arctic zone of Russia, per 100 thousand population. Source: Federal State Statistics Service. Demographic Yearbook (2017). 


\section{Pilot study of eating behaviour in Arkhangelsk}

In March - June 2018, the authors conducted a survey of high school, college, and university students in Arkhangelsk. The obtained data for a sample of 150 students aged 1824 contains some preliminary information about the eating patterns of the youth in one of the cities of the Arctic zone. The sample was equally distributed across the three mentioned types of educational institutions. The survey included questions about the number of daily meals, the composition of lunch dishes, whether or not a snack or afternoon tea was consumed, the composition of a snack, and students' assessment of the quality of their food.

The results of the survey showed that almost one third of the college and university students eat twice a day ( $24 \%$ of each sub-group), while the proportion of high school students following this pattern is minimum (10\%). Over a third of university students $(36 \%)$ and nearly a third of college students (32\%) take three meals a day. Almost half of the surveyed high school students (44\%) eat four times a day, while university and college students chose this answer much less frequently ( $22 \%$ and $14 \%$ respectively). Five meals a day were reported by $26 \%$ of college students and $22 \%$ of high school students. Among university students, five meals a day is the most unpopular answer ( $8 \%$ of respondents). Finally, six and more meals a day were reported by only $10 \%$ of university students and $4 \%$ of college students (Fig. 4). This is most likely because nutrition of high school students is overseen by parents, and the fact that schools provide meals for their students, while college and university students control their nutrition issues by themselves.

The majority of students consider their snacks unhealthy. At that, high school students in Arkhangelsk are more often convinced that "snacking" is healthy, while students of universities and colleges often note that their eating habits are unhealthy (Fig. 5).

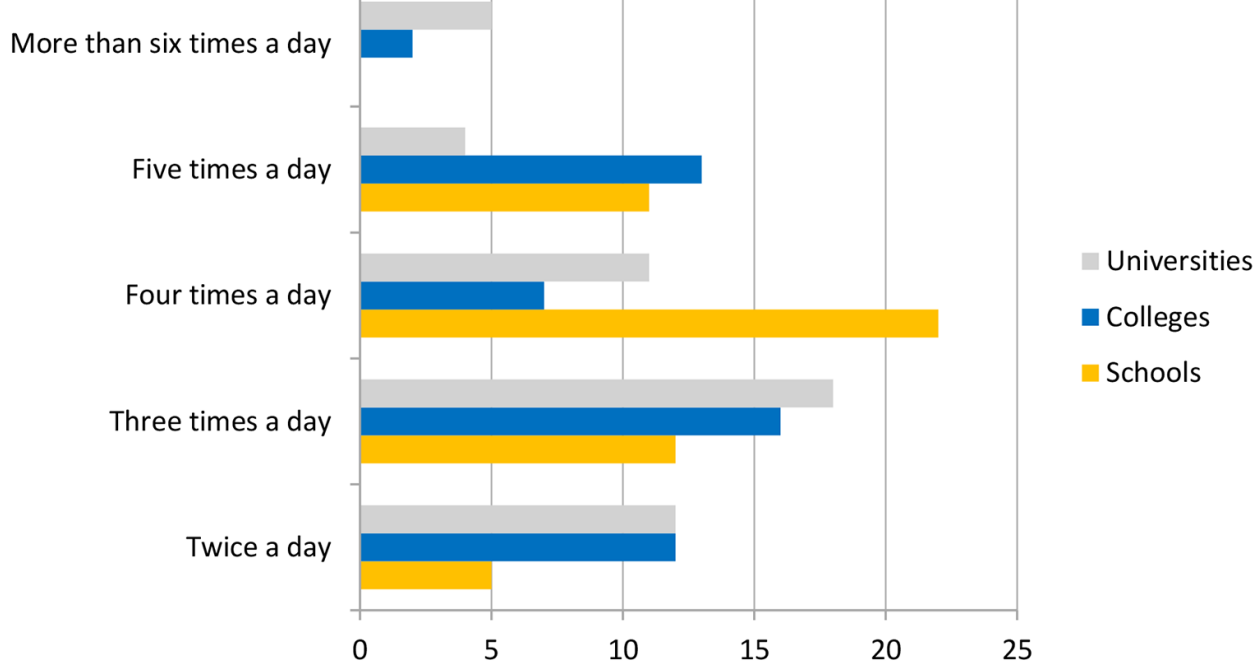

Figure 4. Distribution of answers to the question "How many times a day do you eat — how many meals do you have, including breakfast, lunch, dinner, and light snacks?", number of respondents. Source: estimated by authors on the basis of the conducted survey. 


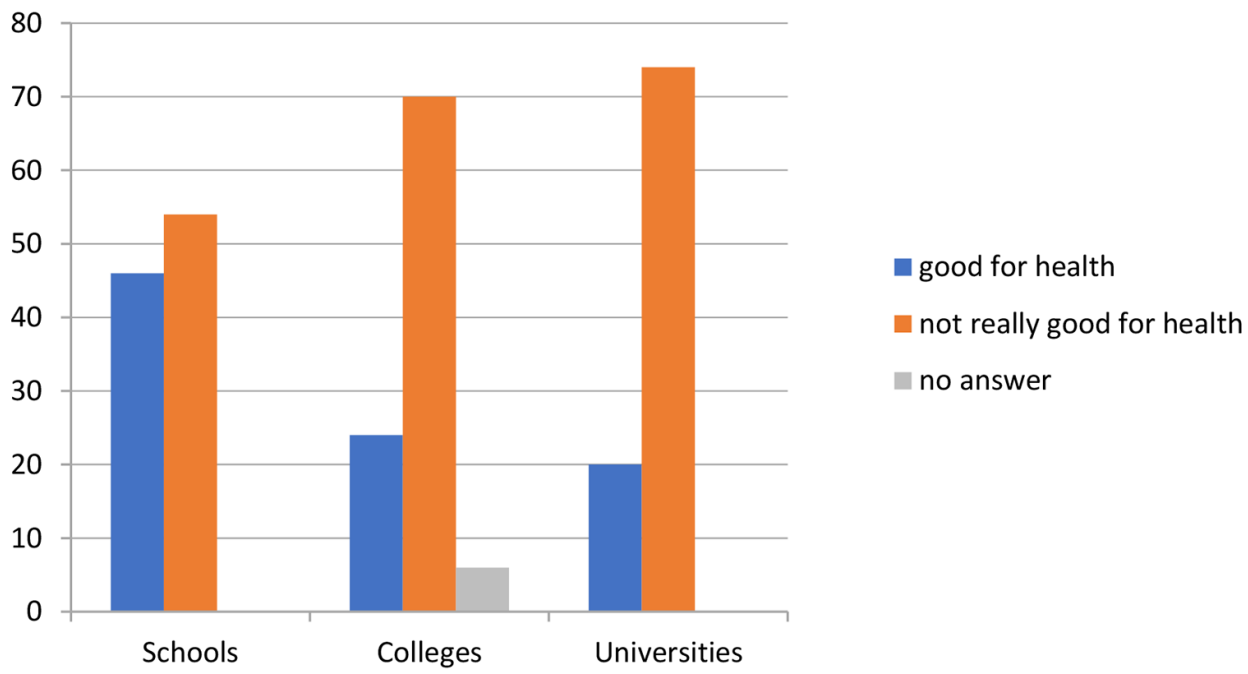

Figure 5. Distribution of answers to the question "How would you estimate your snacking?", \%. Source: estimated by authors on the basis of the conducted survey.

For high school students, it is more common not to eat after 11 p.m. or to limit themselves to a glass of kefir or milk. The habit of a "filling" supper is more often reported by college students (a meal consisting of meat or sausage with garnish, etc.). Additional differences were found in the distribution of answers by gender. Boys and girls studying at schools have different attitudes to a late supper, with $28 \%$ of girls refraining from eating after 11 p.m. and $56 \%$ of girls drinking a glass of kefir or milk, which is high compared to boys, who more often prefer a more filling late dinner (Fig. 6).

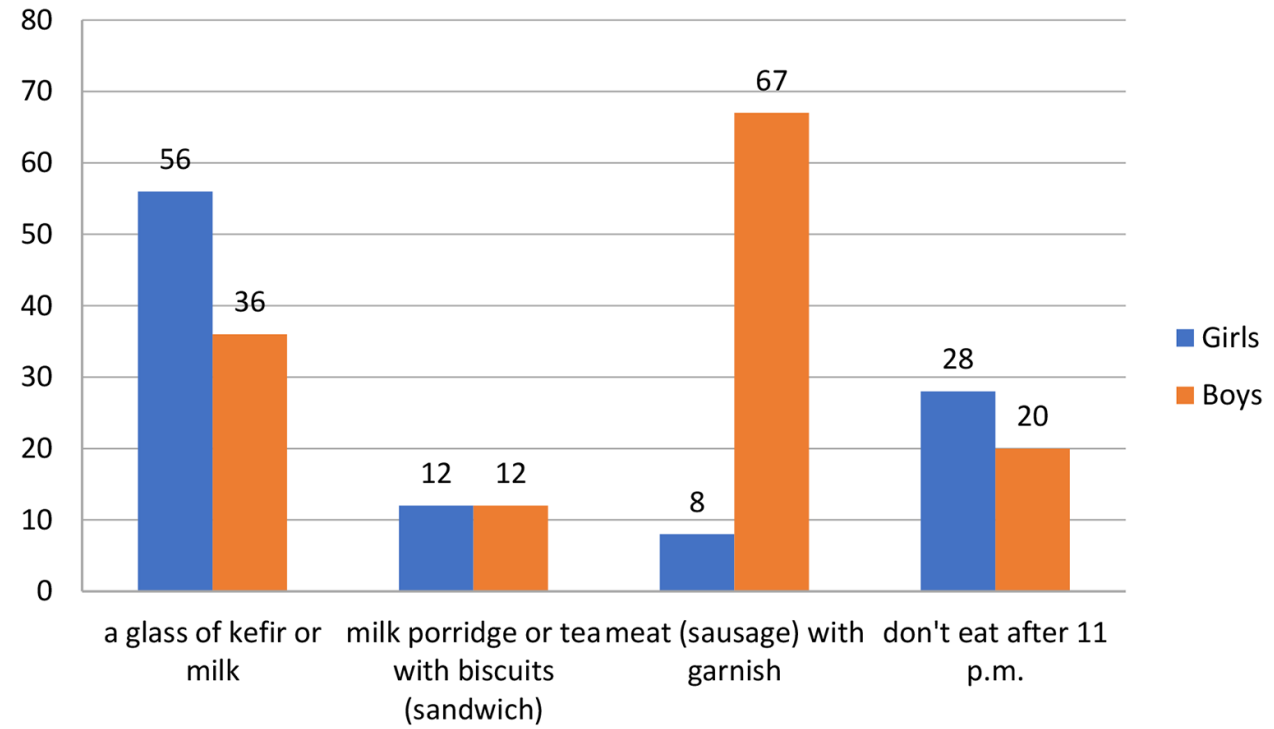

Figure 6. Distribution of high school students' answers to the question "Do you eat before bed (after 11 p.m.)?", \%. Source: estimated by authors on the basis of the conducted survey. 
Most of the respondents do not experience any specific emotions if they consume not entirely healthy food as a snack. At the same time, $12 \%$ of high school students noted that they feel a sense of pride if during a snack they adhere to the norms of a healthy diet (Fig. 7).

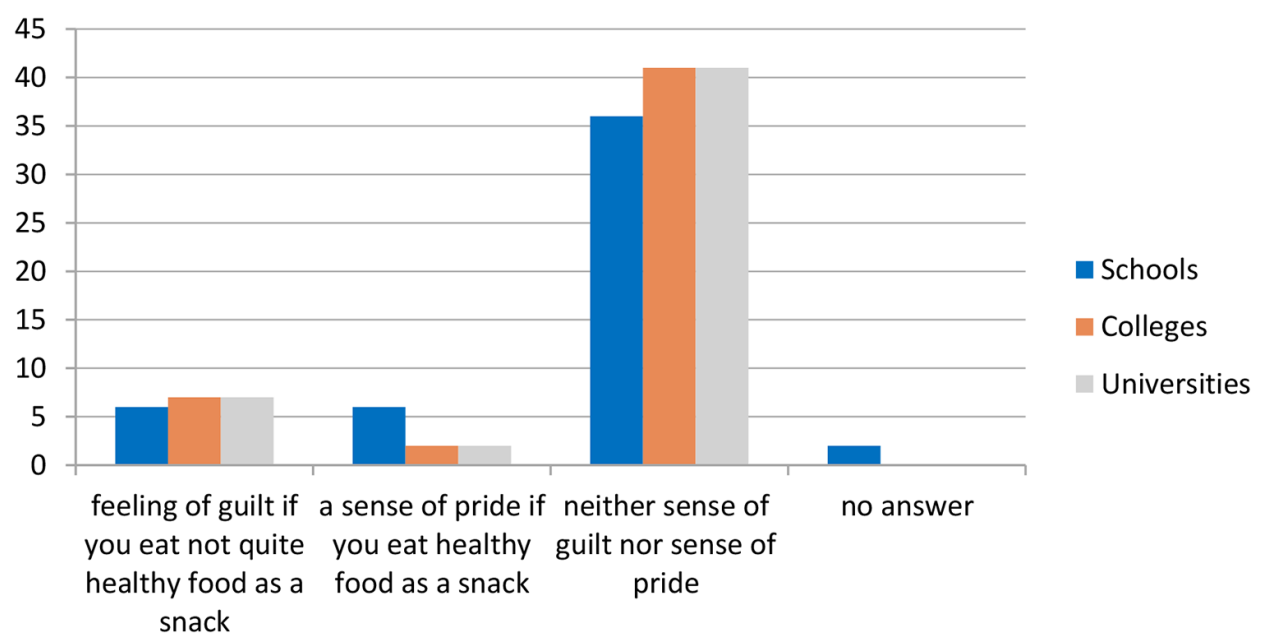

Figure 7. Distribution of answers to the question of how they feel about their snack, \%. Source: estimated by authors on the basis of the conducted survey.

Thus, on the basis of the conducted research, it can be concluded that a significant part of the youth in Arkhangelsk have irregular eating habits and give a rather low assessment of the structure of their own nutrition. At the same time, the respondents note the need to optimize nutrition in the future, talking about the "harmfulness" of the consumed refined products (chocolate bars, crisps, flour and confectioneries, carbonated beverages, etc.) with high energy density and reduced nutritional value. However, they are not yet ready to consider the risks of deterioration of their health in an adverse Arctic climate in the medium term due to their current imbalanced nutrition, which indicates their poor awareness of the relationship between health conditions in the Arctic zone and nutrition culture.

University students show a greater commitment to balanced nutrition than college students, but it is college and university students that disregard frequency of nutrition, which can be a consequence of inadequate catering arrangement and its affordability at local educational institutions.

This note is the first step in researching the eating habits of the youth in the Arctic regions of Russia. Further specification of the obtained results, an in-depth analysis of morbidity and mortality statistics, as well as conducting surveys of young people on representative samples at the urban and regional level may enable formulating applied recommendations to improve the eating habits of the youth.

\section{Reference List}

WHO (2004) The Global Strategy on Diet, Physical Activity and Health (DPAS). URL: https://www. who.int/nmh/wha/59/dpas/en/ 
Mironova YuG (2016) Osobennosti samosokhranitel'nogo povedeniya sovremennoi studencheskoi molodezhi [The Features of self-preservation behaviour of modern students]. Teoriya i praktika obshchestvennogo razvitiya [Theory and practice of social development] 6: 48-51. URL: http:// teoria-practica.ru/rus/files/arhiv_zhurnala/2016/6/sociology/mironova.pdf (in Rusian)

Petrova PG (2019) Ehkologo-fiziologicheskie aspekty adaptatsii cheloveka k usloviyam severa [Ecological and physiological aspects of human adaptation to the conditions of the North]. Vestnik Severo-Vostochnogo federal'nogo universiteta imeni M.K. Ammosova. Seriya «Meditsinskie naukI» [Bulletin of M.K. Ammosov North-Eastern Federal University. "Medical Science" Series] 2(15): 29-38. https://doi.org/10.25587/SVFU.2019.2(15).31309

Syrtsova LE, Abrosimova YuE, Lopatina MV (2016) Gramotnost' v voprosakh zdorov'ya: soderzhanie ponyatiya [Health literacy: content of the concept]. Profilakticheskaya meditsina [Preventive medicine] 19(2): 58-63. https://doi.org/10.17116/profmed201619258-63

Chashchin VP, Gudkov AB, Popova ON, Odland YгO, Kovshov AA (2014) Kharakteristika osnovnykh faktorov riska zdorov'ya naseleniya, prozhivayushchego na territoriyakh aktivnogo prirodopol'zovaniya $\mathrm{v}$ Arktike [Description of main health deterioration risk factors for population living on territories of active natural management in the Arctic]. Ehkologiya cheloveka [Human Ecology] $1: 3-12$.

Shabunova AA, Korchagina PS (2012) Tsennostnye ustanovki i povedencheskie praktiki kak znachimye faktory samosokhranitel'nogo povedeniya molodezhi [Values and Behavioral Practices as Significant Factors of Self-Preserving Behaviour of the Youth]. Ehkonomicheskie i sotsial'nye peremeny: fakty, tendentsii, prognoz [Economic and social changes: facts, trends, forecast] 6(24): 138-45.

Abraham S, Noriega BR, Shin JY (2018) College Students Eating Habits and Knowledge of Nutritional Requirements. Journal of Nutrition and Human Health: 2(1): 13-7.

Ajzen I (1985) From Intentions to Actions: A Theory of Planned Behavior. In: Kuhl J, Beckman J (Eds) Action-control: From cognition to behavior. Springer, Heidelberg. Pp. 11-39.

Ajzen I (1991) The Theory of Planned Behavior. Organizational Behavior and Human Decision Processes: 50(2):179-211. https://doi.org/10.1016/0749-5978(91)90020-T

Barnes SP, Brown KM, McDermott RJ, Bryant CA, Kromrey J (2012) Perceived Parenting Style and the Eating Practices of College Freshmen. American Journal of Health Education: 43(1): 8-17.

Das BM, Evans EM (2014) Understanding Weight Management Perceptions in First-Year College Students Using the Health Belief Model. Journal of American College Health: 62(7): 488-97. https:// doi.org/10.1080/07448481.2014.923429

McDermott MS, Oliver M, Simnadis T, Beck EJ, Coltman T, Iverson D, Caputi P, Sharma R (2015) The Theory of Planned Behaviour and Dietary Patterns: A Systematic Review and Meta-Analysis. Preventive Medicine: 81: 150-6. https://doi.org/10.1016/j.ypmed.2015.08.020

Other data sources:

Demographic Yearbook (2017) Federal Service for State Statistics. Statistical yearbook. M.: Rosstat. URL: https://gks.ru/bgd/regl/B17_16/Main.htm (in Russian)

Healthcare in Russia (2017). Federal Service for State Statistics. Statistical yearbook. M.: Rosstat. URL: https://www.gks.ru/free_doc/doc_2017/zdrav17.pdf. (in Russian)

\section{Information about the authors}

- Olga B. Khoreva, Cand. Sc. (Econ.), Associate Professor, Department of Territorial Development Management and Regionalism, National Research University Higher School of Economics, Moscow, Russia. E-mail: ohoreva@hse.ru 
- Tamara Nezhina, PhD, Associate Professor, Department of Economics and Management in Non-Governmental Non-Profit Organizations, National Research University Higher School of Economics, Moscow, Russia. E-mail: tgnezhina@hse.ru

- Elena Anatolievna Tarasenko, Cand. Sc. (Soc.), Associate Professor, Department of Health Management and Economics, National Research University Higher School of Economics, Moscow, Russia. E-mail: etarasenko@hse.ru

- Ekaterina Nikolaevna Tamitskaya, Senior Lecturer, Department of Philosophy and Sociology, Northern (Arctic) Federal University named after M.V. Lomonosov, Arkhangelsk, Russia.E-mail: e.tamickaya@narfu.ru

- Konstantin Zaykov, PhD, Associate Professor of the Department of Regional Studies, International Relations and Political Science, Northern (Arctic) Federal University named after M.V. Lomonosov, Arkhangelsk, Russia.E-mail: k.zaikov@narfu.ru 